\title{
أثر التحولات الحضرية لمدن أقليم الدلتا فى تغير الطابع المعمارى \\ The impact of Urban Transformation of Delta Region Cities on Architectural Character Changing
}

Abstract

The Last recent saw clear increase in the operations and movement of construction and that the increase followed by a different style in the architectural movements followed and the architectural character of those establishments. The problem of the research is to know the architectural character of the outskirts of the city in terms of urban transformations of Delta Region Cities on Architecture Character Changing and the integration of some villages in the neighboring cities, because of increasing of the population and migration from villages to cities and the demolition and replacement of traditional local buildings with other modern concrete buildings, which led to the appearance of architecture reflecting postmodern thinking and the use of Western architectural vocabulary and return to nostalgia to the past. The importance of research is to arrive and forecast of the city in the future and to monitor and document the current urban and architectural reality of the outskirts of the city of Shebin Al-Koum to identify the basic architectural and architectural aspects of the city parties through the urban shape of the city and the architectural form of the building. The aim of the research is to document the current architectural form of architecture in the outskirts of Shebin El Koum and to know whether the city's extensions were dominated by rural or urban character.

The reserch depends on the case study methodology to determine the general shape of the architectural character in the outskirts of Shebin Al-Koum city and the shape of the architecture in terms of the study of the history of Mith Khaqan.

The study consists of five parts, Where the first and second part discusses the theoretical framwork related to the concepts of post-modern architecture and Historicism. The Third part discusses the historical development of architecture in the city of Shebin El Koum in terms of the different architectural character throught out the ages that influenced the city. While the fourth part deals with the case study of the Mait Khaqan and know what is the architectural character that affects of the Mait Khaqan. The reserch concluds with the necessary results to achieve the architrctural character and architectural features of the buildings in the outskirts of shebin el koum city.

\section{ملخص البحث}

شهدت الفترة الاخيرة زيادة و اضحة فى عمليات وحركة البناء، وكانت

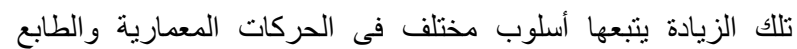

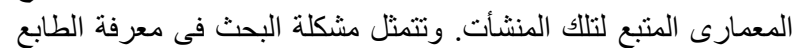

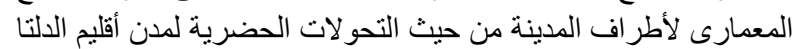

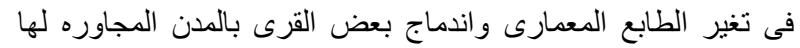

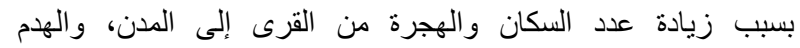

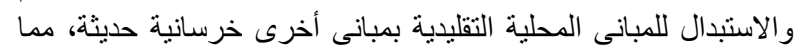

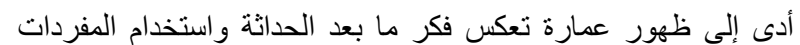

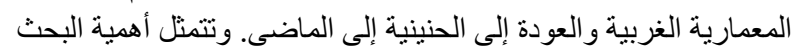

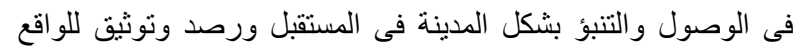

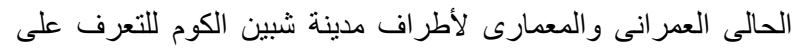

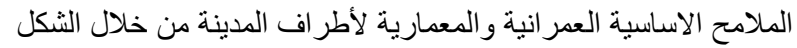

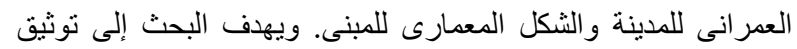

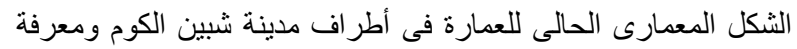

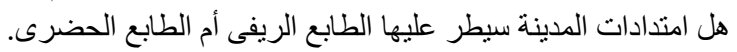

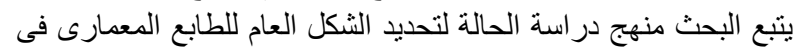

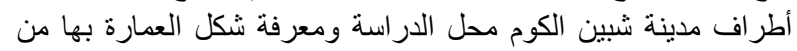
حيث در اسة شياخة ميت خاقان.

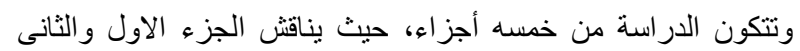

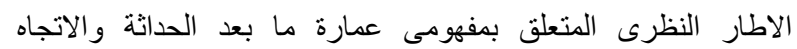
التاريخى، ويتناول الجزء الثالث التُى التطور التاريخى للعمارة في مدينة

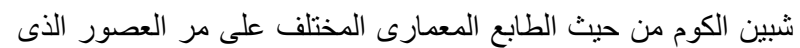

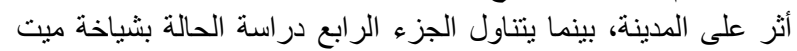

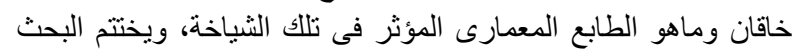

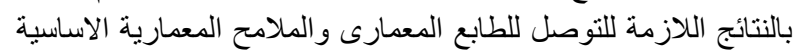

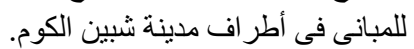

$$
\begin{aligned}
& \text { الكلمات المفتاحية : الطابع المعمارى - عمارة ما بعد الحداثة- الاتجاه } \\
& \text { التاريخى- العمارة المحلية- شبين الكوم }
\end{aligned}
$$

Key words: Architectural Character - Post Modern Architecture - Historicism - Vernacular Architecture Shebin El-Kom. 


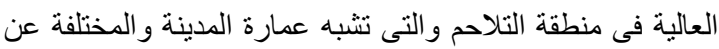

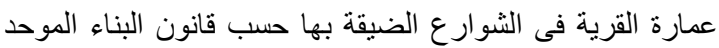

رقم 119.

وبالتالى يهدف البحث إلى نوثيق الشكل المعمارى الحالى للعمارة فى الثى

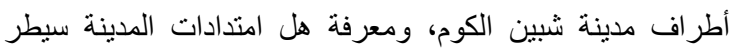

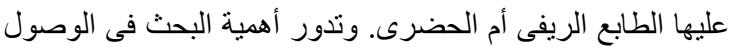

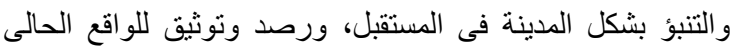

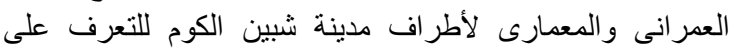
الملامح الاساسية العمر انية والمعمارية لأطر اف المدينة من خلال:

• الثكل العمر انى للمدينة.

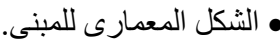

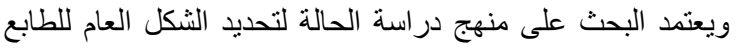

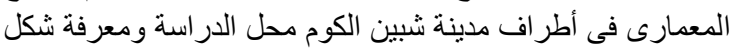
العمارة بها من حيث در اسة شياخة ميت فئن خاقان.

3- عمارة ما بعد الحداثة

بدأت عمارة ما بعد الحداثة عندما اصبحت عمارة الحمارة الحداثة رتيبة

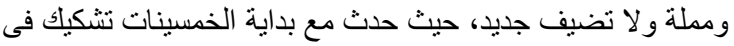

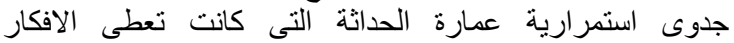

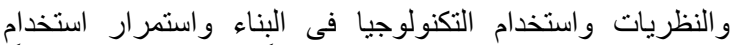

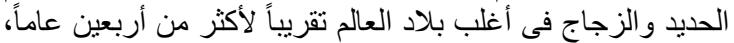

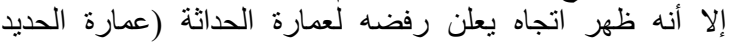

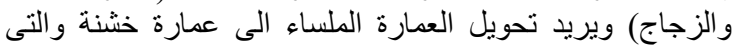

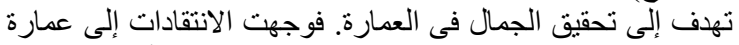

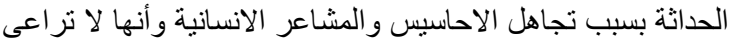

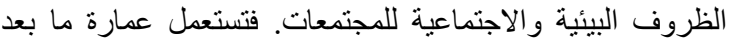

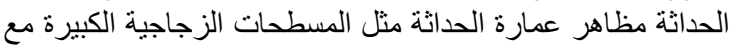

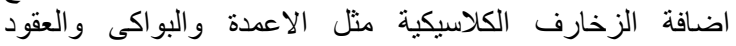

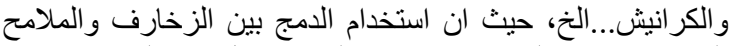

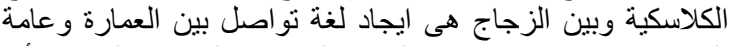

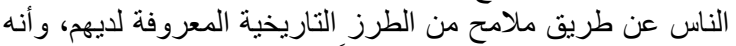

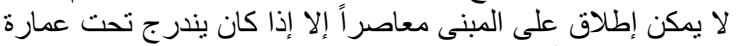

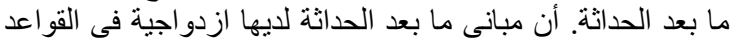

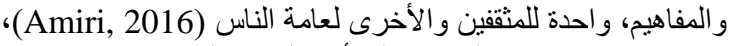

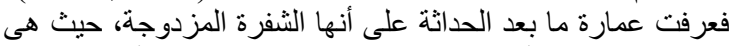

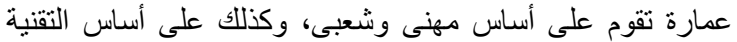

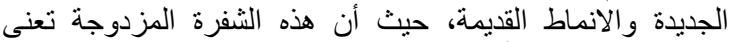

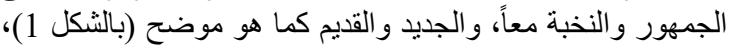

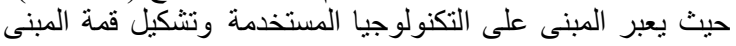

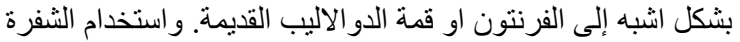

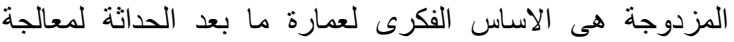

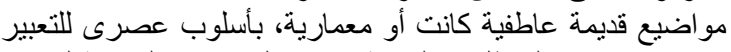

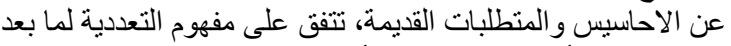

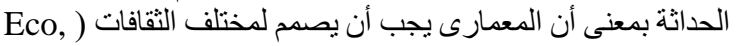

دائماً ما تكون الحركة المعمارية نتاجاً معبراً عن الحياة الاجتماية

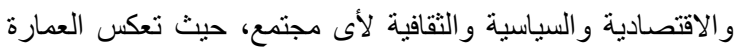

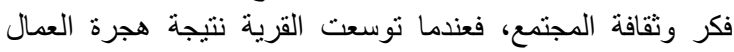

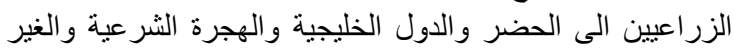

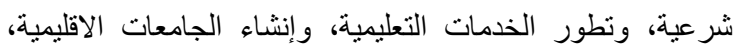

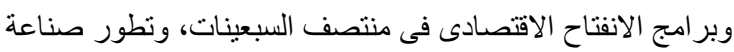

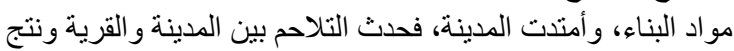

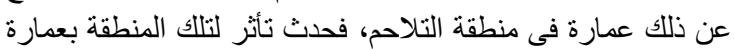

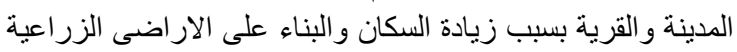

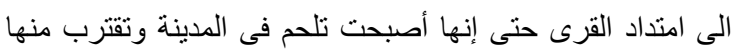

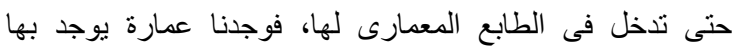

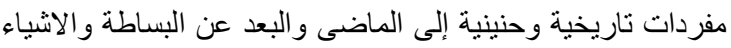

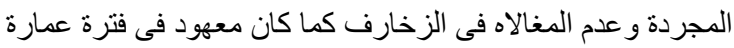

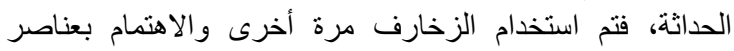

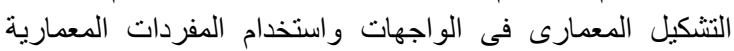

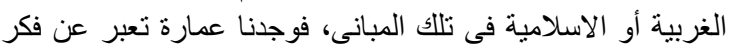

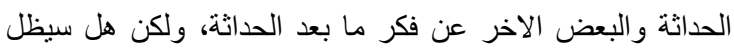

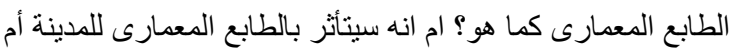
القرية؟

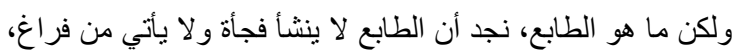

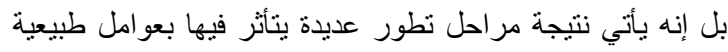

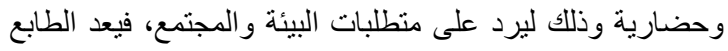

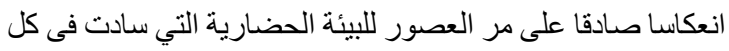

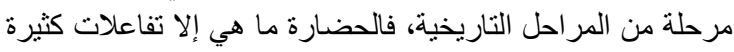

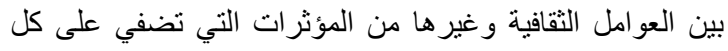

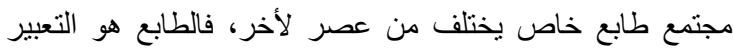

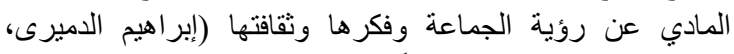

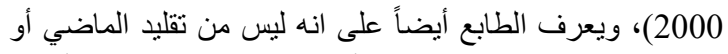

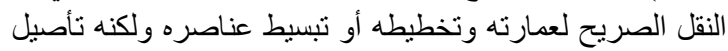

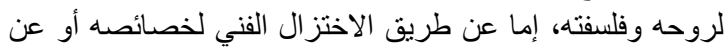

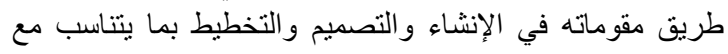
حاضرنا ومستقبلنا (عبد الباقى إبر اهيم، 1982).

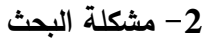

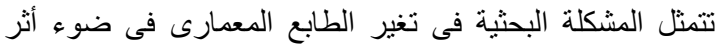

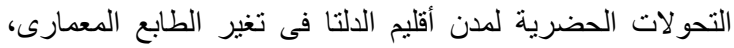

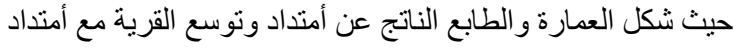

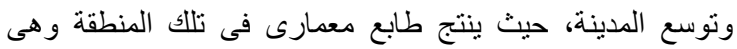

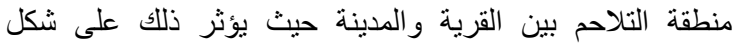

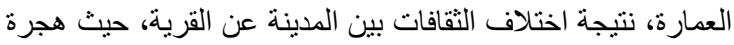

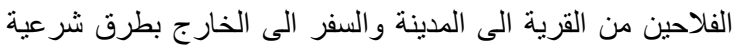

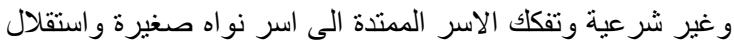

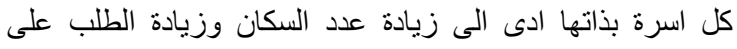

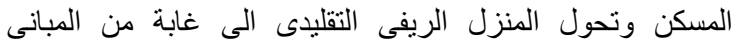

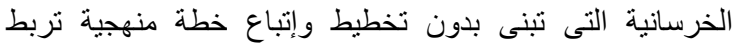

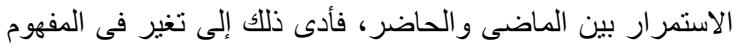

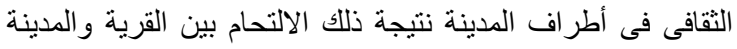

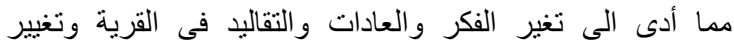

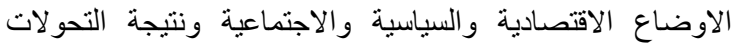

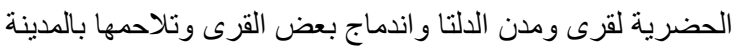

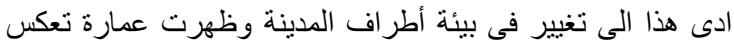




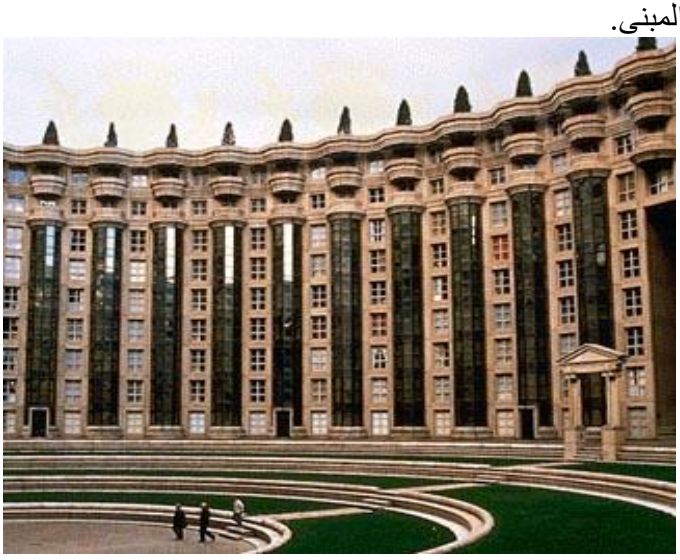

شكل (2) المجمو عة السكنية فى حى مومبر انس، فرنسا، ريكاردو

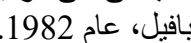

المصدر: www.Great Buildings.com بافل عام

5- التطور التاريخى للعمارة فى مدينة شبين الكوم

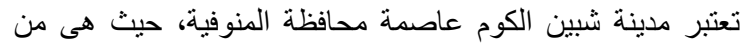

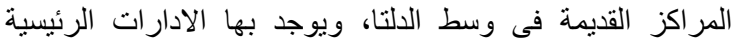

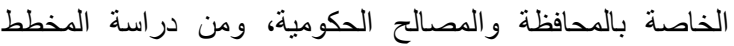

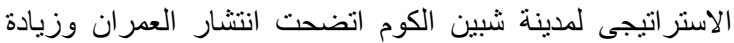

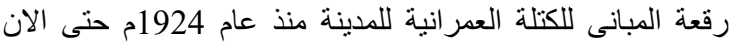

كانت محافظة المنوفية تحت الحكم البريطانى، حيث كانت مصر

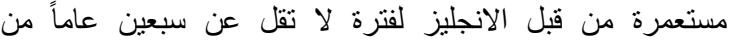
الاحتلال، حيث أن الاستعمار هو شكل من أشكال السيطرة على لأنى

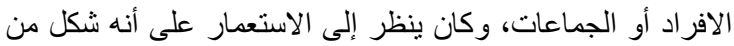

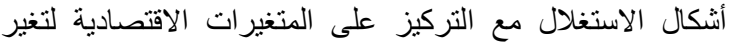

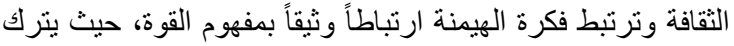

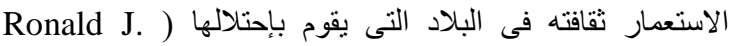

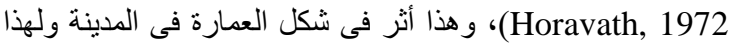

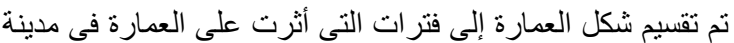
شبين الكوم إلى: تمبع

• العمارة التقليدية أو المحلية: تعتبر العمارة المحلية فى شبين الكوم

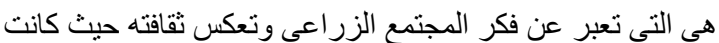

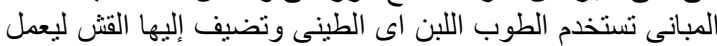

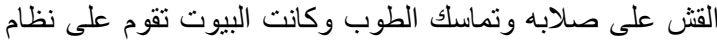

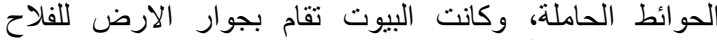

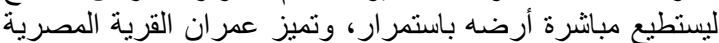

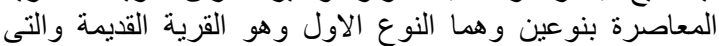

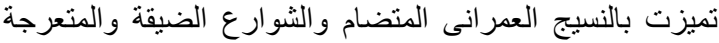
ونر اها فى قلب القرية من الداخل لانها ماز الت الت حتى الان التئ منماسكة

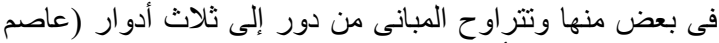

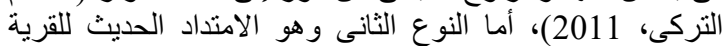

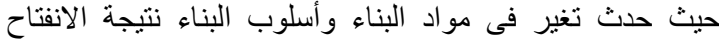

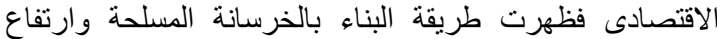

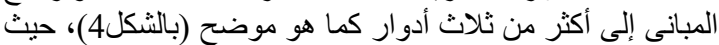

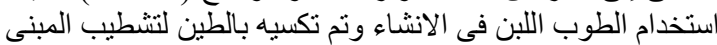

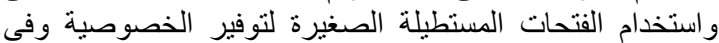

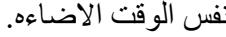

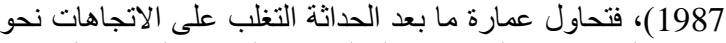

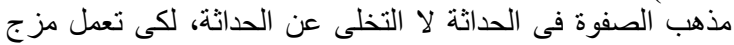

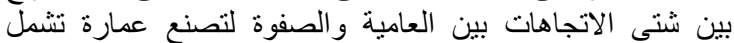

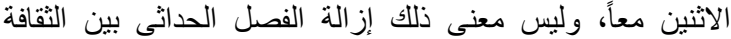

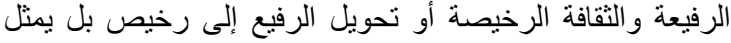
اتساع للغة التخاطب عند الناس (Jenks, 1984).

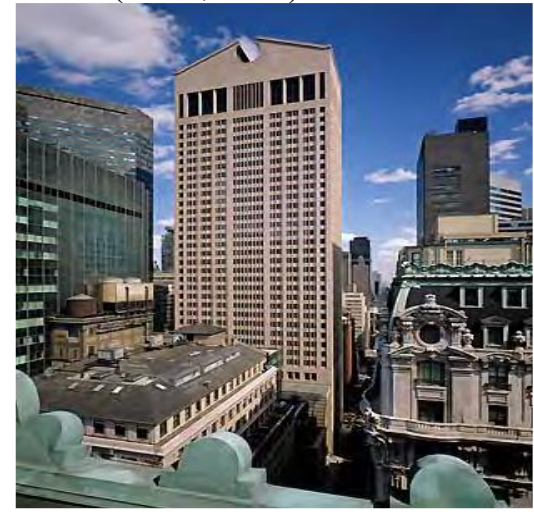

شكل (1) مبنى AT \& T للمعمارى فيليب جونسون، نيويورك، 1982-1978

المصدر: www.Great Buildings.com

4- الاتجاه التاريخى لعمارة ما بعد الحداثة

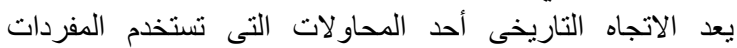

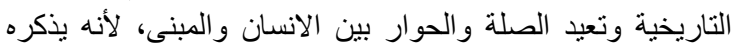

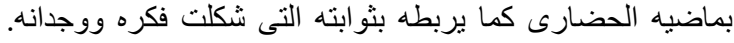

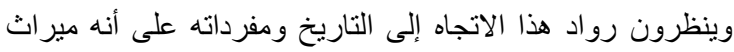

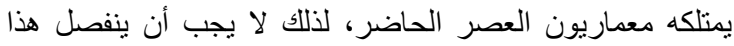

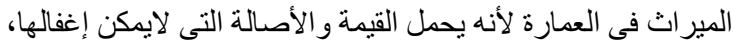

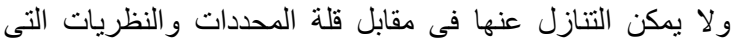
فرضتها عمارة الحداثة على أسلوب العمل فلى العلى المعمارى (ميرفت

الثافعى، 1993).

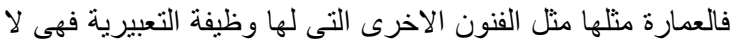

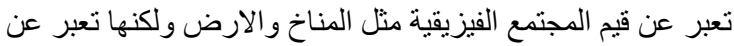

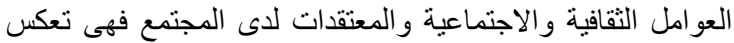

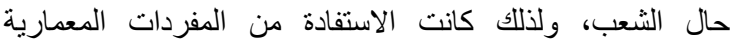

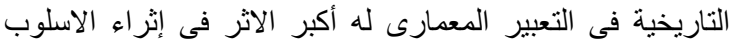

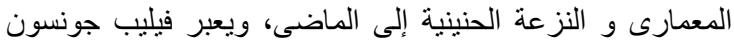

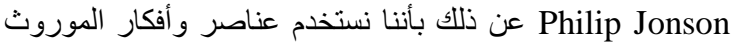

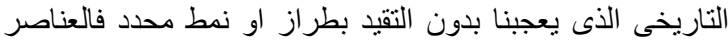

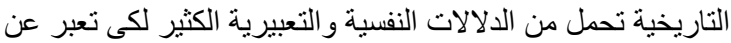

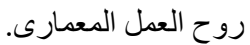

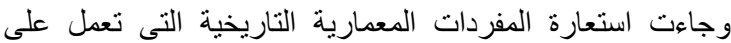

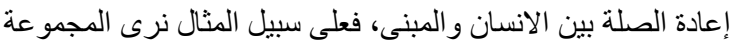

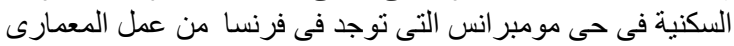

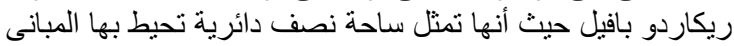

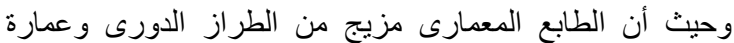

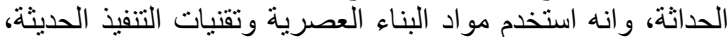

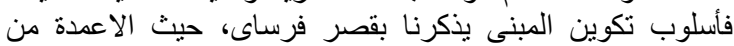

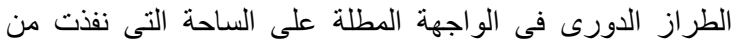

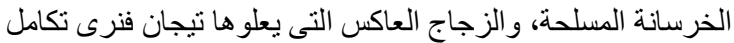

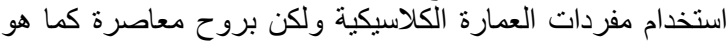

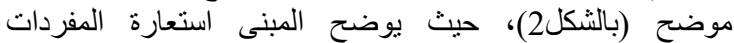
المعمارية التاريخية من استخدام الطراز الدورى مع مزجها 


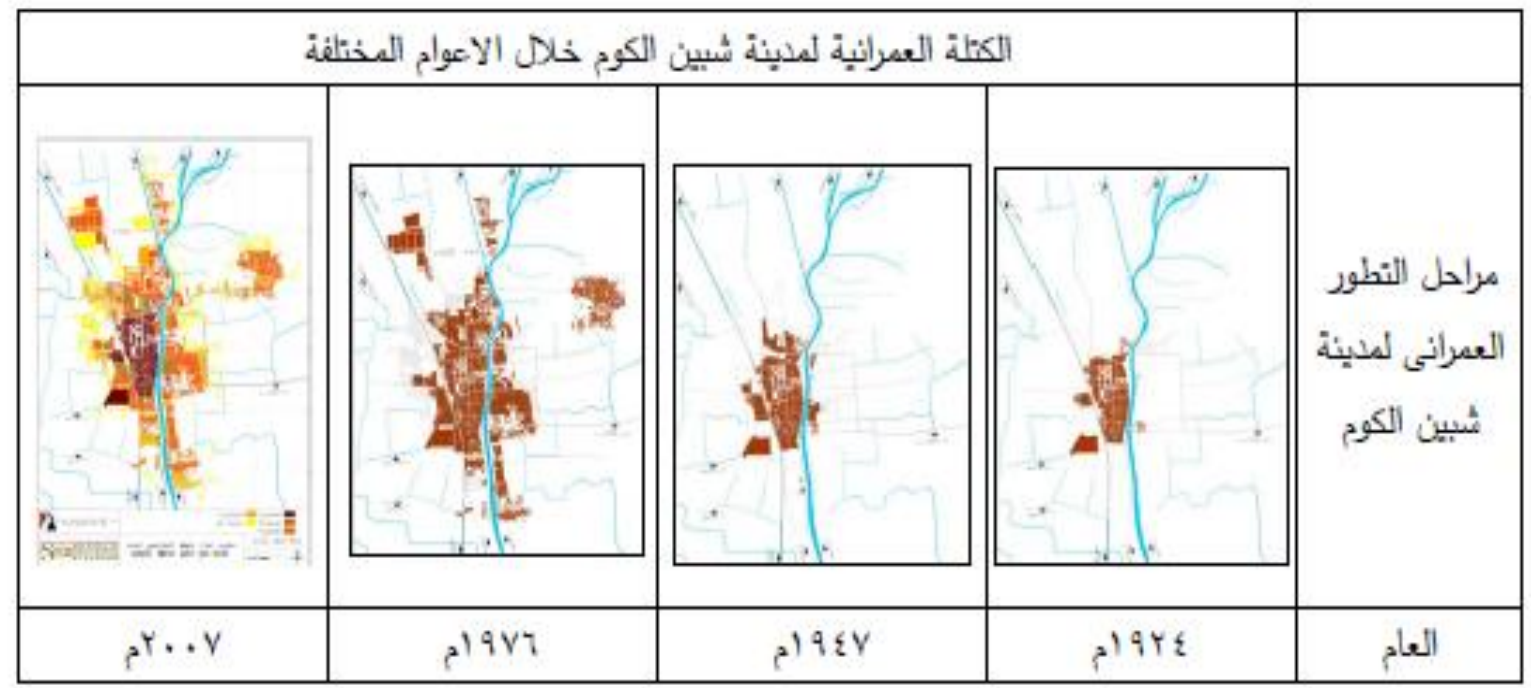

شكل (3) مر احل التطور العمر انى لمدينة شبين الكوم خلال الاعو ام المختلفة، مصر.

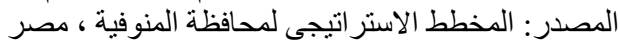

1. حركة التعمير الضخمة التى تبنتها الثورة فيى بناء المصانع و الأحياء السكنية ومبانى الخدمات.

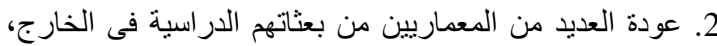

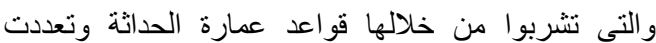
الامثلة الدالة على عمارة الحداثة.

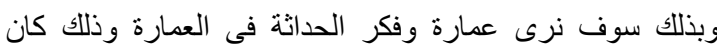

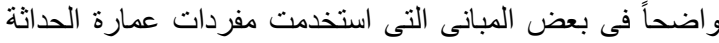

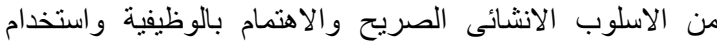

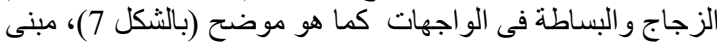

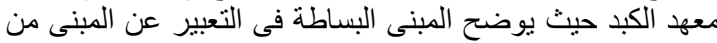

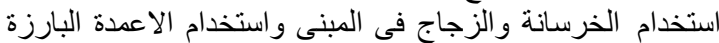

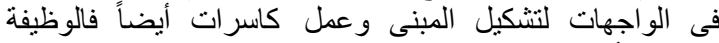

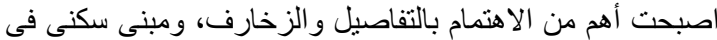

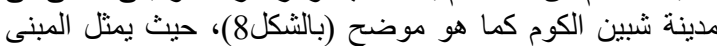

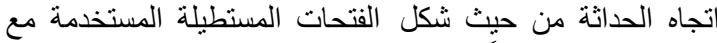

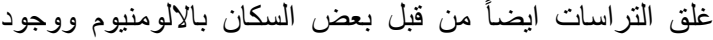

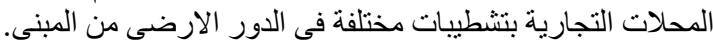

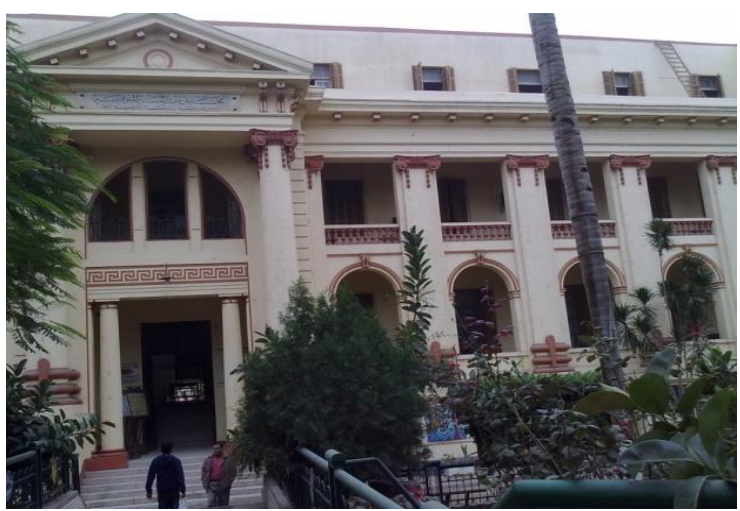

شكل (5) مدرسة الثانوية بنات القديمة، شبين الكوم، المنوفية،

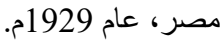

المصدر: الباحث

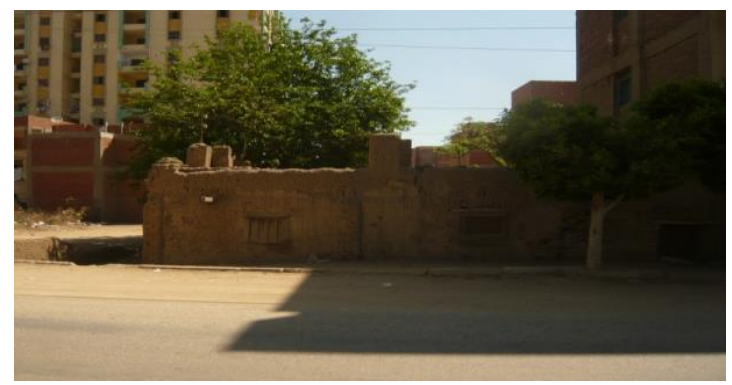

شكل (4) المسكن التقليدى القديم بمدينة شبين الكوم، المنوفية، مصر. المصدر : الباحث

• فترة الاحتلال البريطانى من 1882-1952

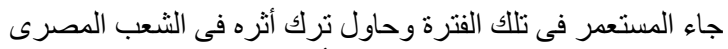

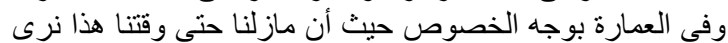

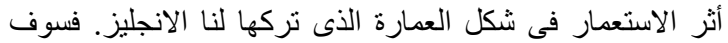

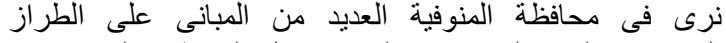

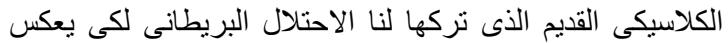

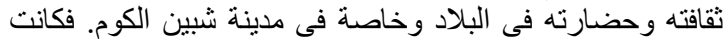

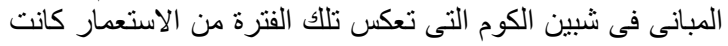

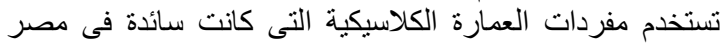

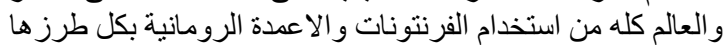

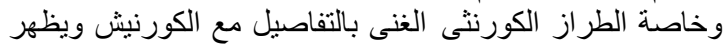

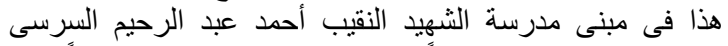

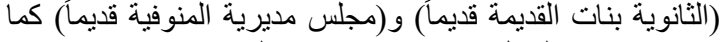

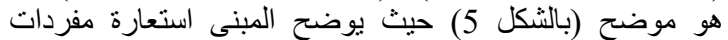

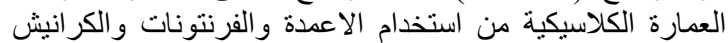

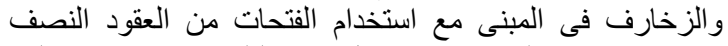

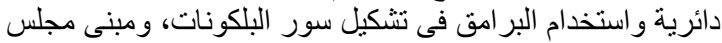

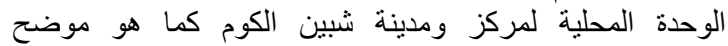

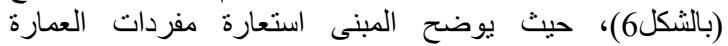

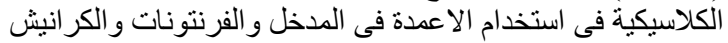
فى المبنى و استخدام الفتحات المستطيلة فى النو افذ للمبنى.

\section{• فترة ما بعد الاستعمار (عمارة الحداثة) من 1952 حتى}

1980

عندما انتهت فترة الاحتلال الانجليزى التى شهذتها مصر بعد ثورة يوليو عام 1952 بدا يتضح الاتجاه العام لعمارة الحداثة وقد التصنح هذا الاتجاه لسببين رئيسين وهما: 


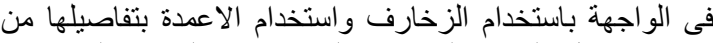

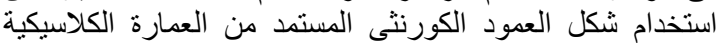

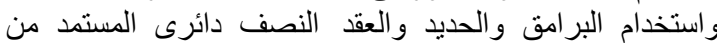

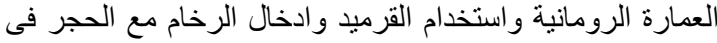

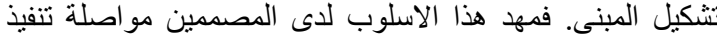

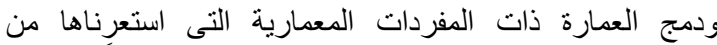

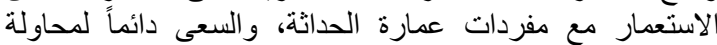

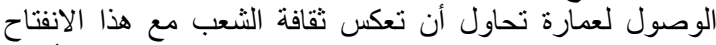

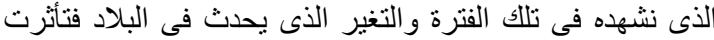
عمارة ما بعد الحداثة بكل ذلك. لكن.

6- دراسة الحالة ميت خاقان

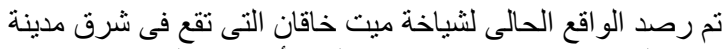

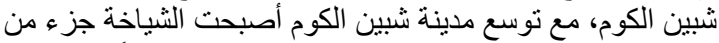

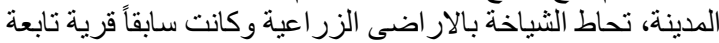

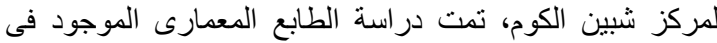

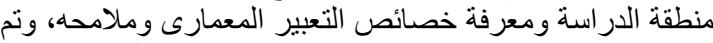

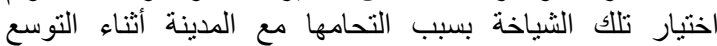

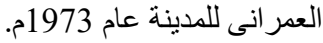

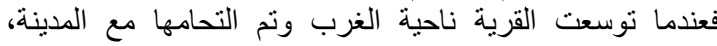

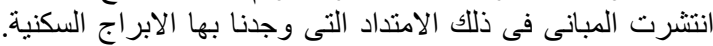

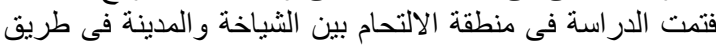

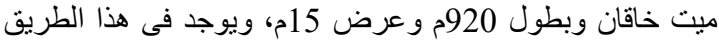

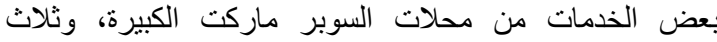

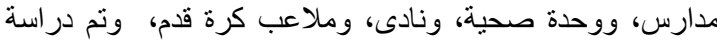

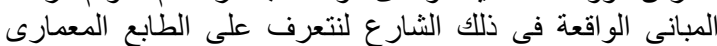

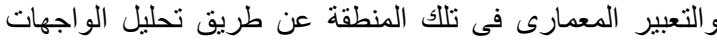

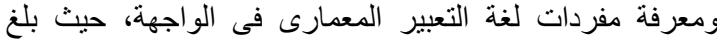

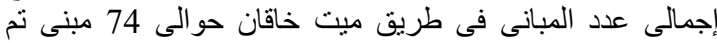

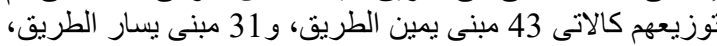

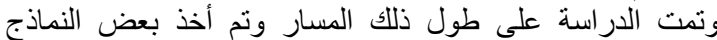

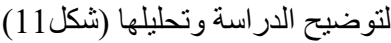

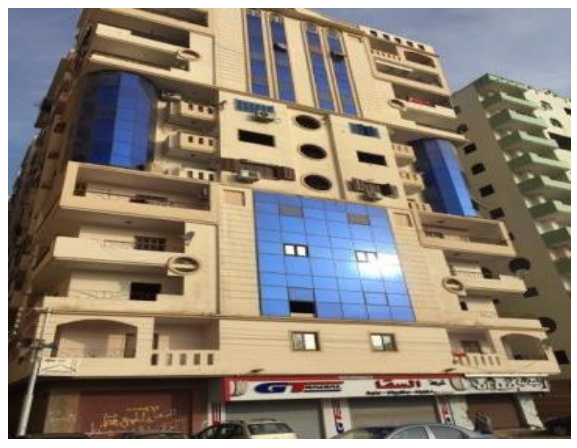

شكل (9) شكل المبانى فى مدينة شبين الكوم، المنوفية، مصر.

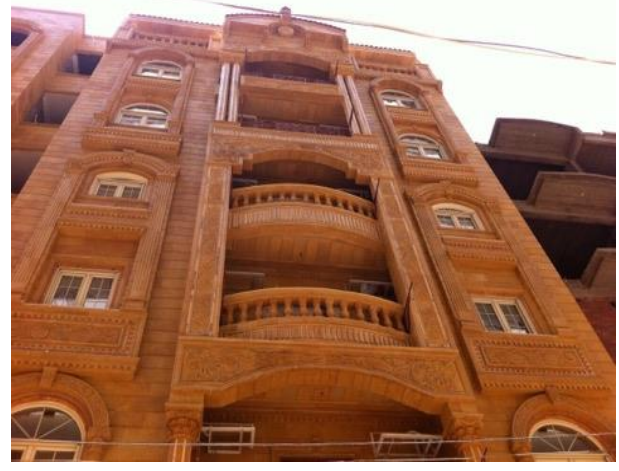

شكل (10) شكل المبانى فى مدينة شبين الكوم، المنوفية، مصر. المصدر : الباحث فئم

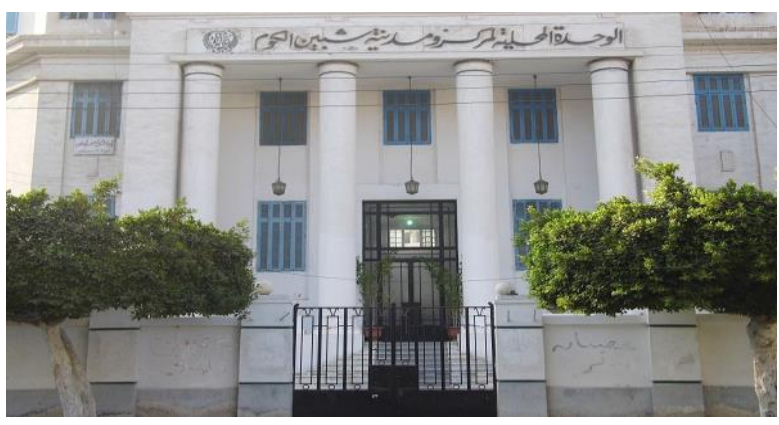

شكل (6) مبنى مجلس المدينة، شبين الكوم، المنوفية، مصر. المصدر: الباحث المثن

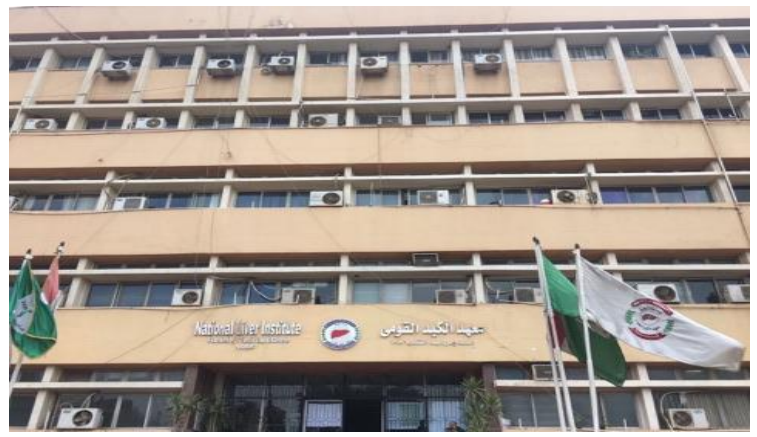

شكل (7) مبنى معهد الكبد القديم، شبين الكوم، المنوفية،

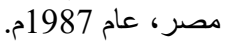
المصدر: الباحث عام

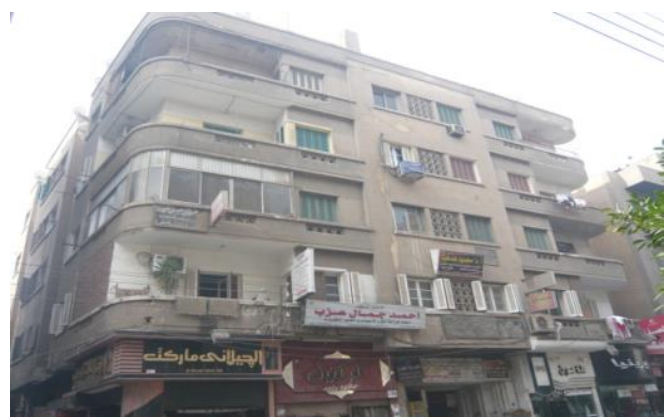

شكل (8) شكل المبانى فى مدينة شبين الكوم، المنوفية، مصر. المصدر: الباحث

• فترة ما بعد الحداثة من 1980م حتى الان

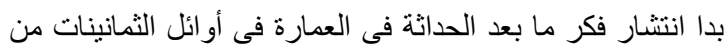

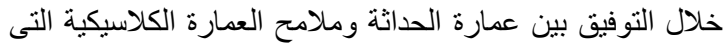

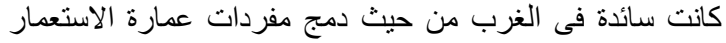

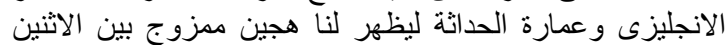

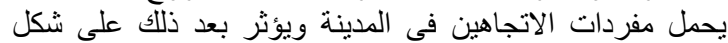

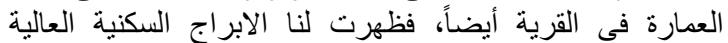

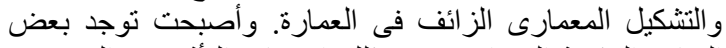

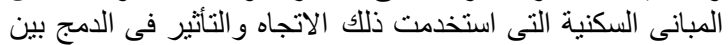
المواد الحديثة والزجاج والئية والمفردات المعمارية الاسلامية التئي التئي

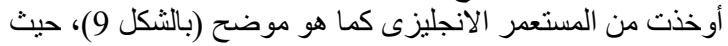

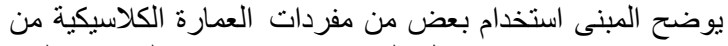

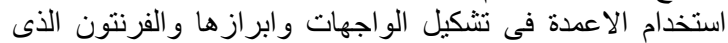

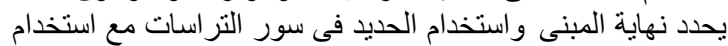

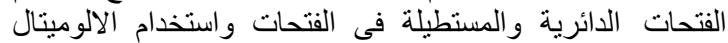

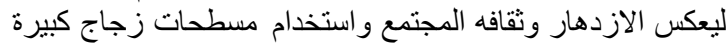

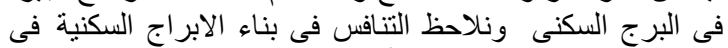

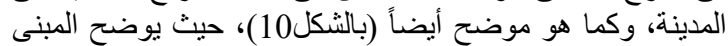

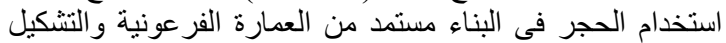



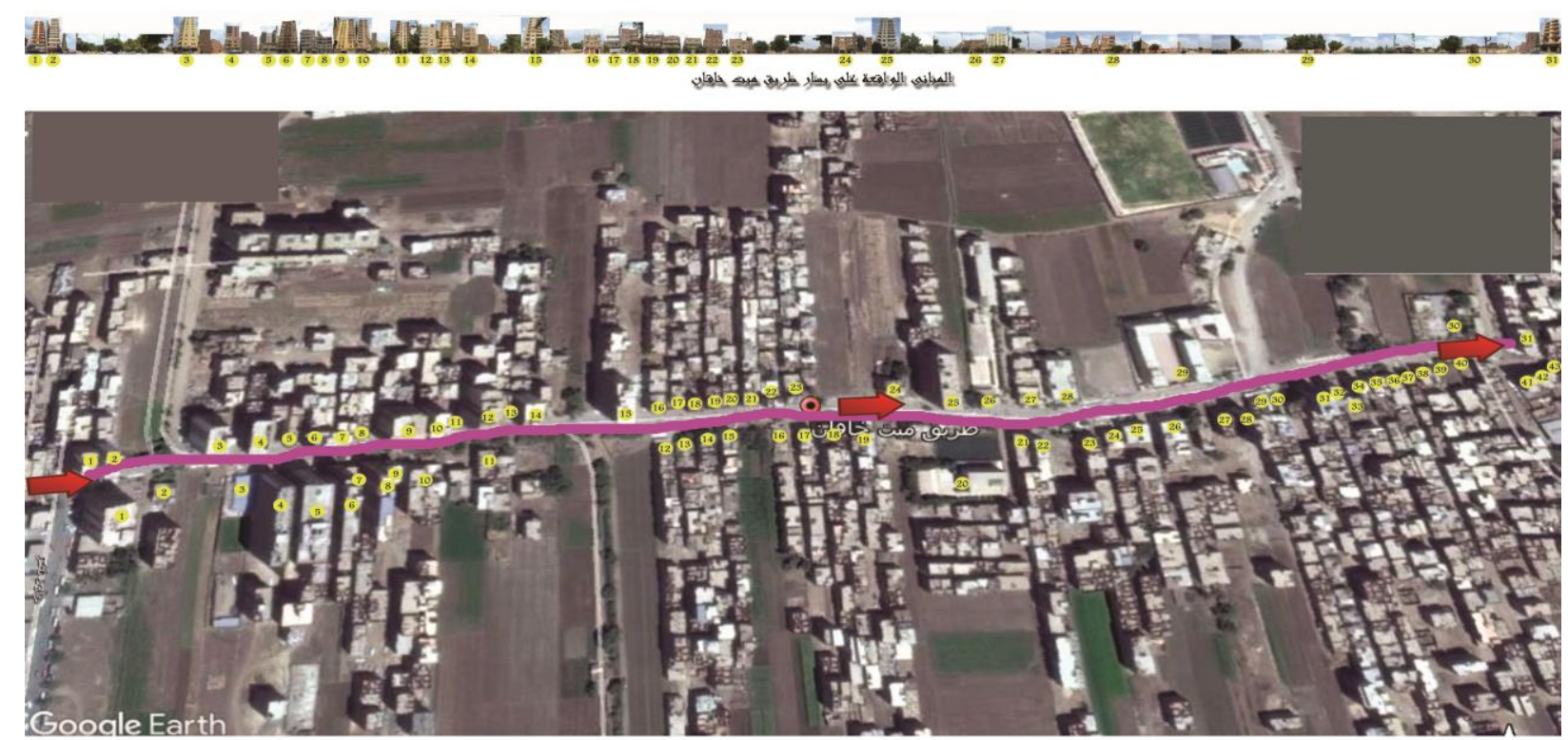

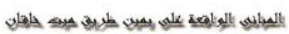

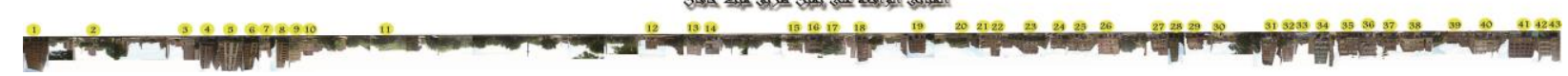

شكل (11) منطقة محل الدراسة وموقع عليه المبانى الو اقعة فى منطقة التلاحم يمين ويسار الطريق. المصدر: الباحث

4) استعمالات الدور المتكرر.

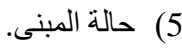

6) العناصر الزخرفية مثل: (الزخارف الجبسية ـ كتابه أسلامية).

7) شكل التراسات.

8) (7) شكل الفتحات.

9) (10) تشطيبات الو اجهات.

10) العناصر التشكيلية مثل: (حديد - برامق الو - اعمدة).

وكما هو موضح بالجدول (1) (1).

3-6 التحليل التفصيلى لبعض المبانى فى منطقة ميت خاقان

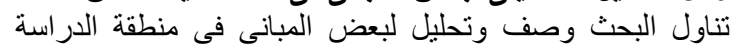

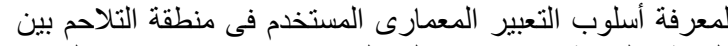

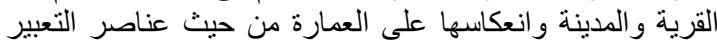

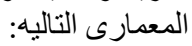

• شكل الفتحات المستخدم فى المبنى. • شكل التر اسات المستخدم فى المبنى.

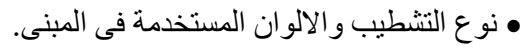

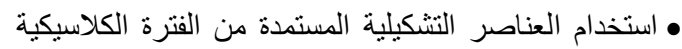
من البر امق أو الحديد المشغول أو الاعمدة. • استخدام العناصر الزخرفية فى المبنى.

1) النموذج (1) برج سكنى مكون من 11 طابق نم استخدام

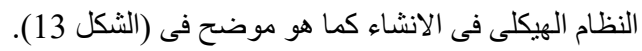

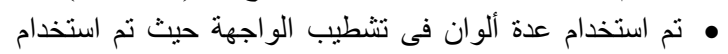

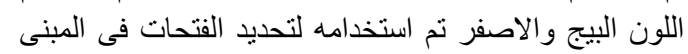

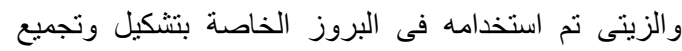

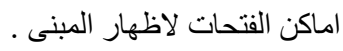

• المبنى لا يوجد به أى زخارف مستخدمة فى تشكيل الو اجهة. • تم استخدام شكل التراس المستطيل والدائرى على ناصية

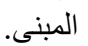

1-6 النمط العمرانى لشياخة ميت خاقان

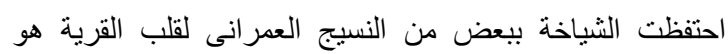

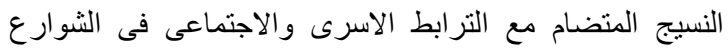

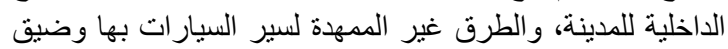

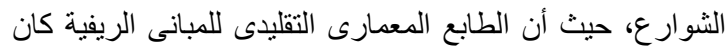

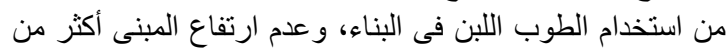

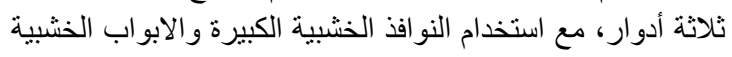

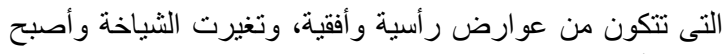

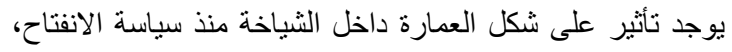

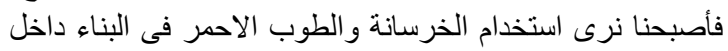

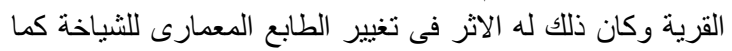

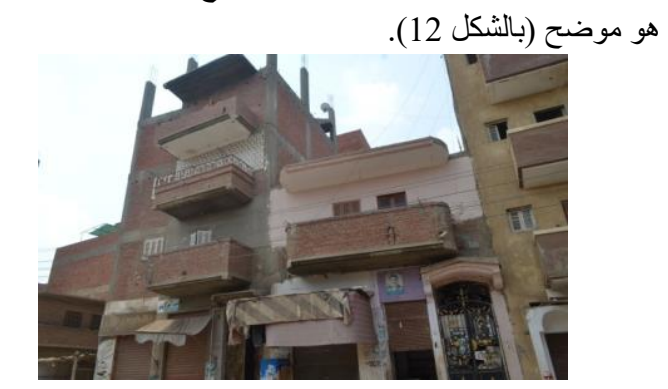

$$
\begin{aligned}
& \text { شكل (12) المبانى الخرسانة واستخدام الطوب الاحمر } \\
& \text { وارتفاع المبانى على شوانى الخرسية وضيقة داخل القرية. }
\end{aligned}
$$
6-2 تحليل الجداول لمنطقة ميت خاقان

سوف يتم تحليل الطابع المعمارى لمنطقة ميت خاقان من خلال المعايير التاليه:

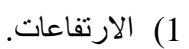
2) (1) نظام الانثاء. 3) استعمالات الدور الارضى. نظ. 


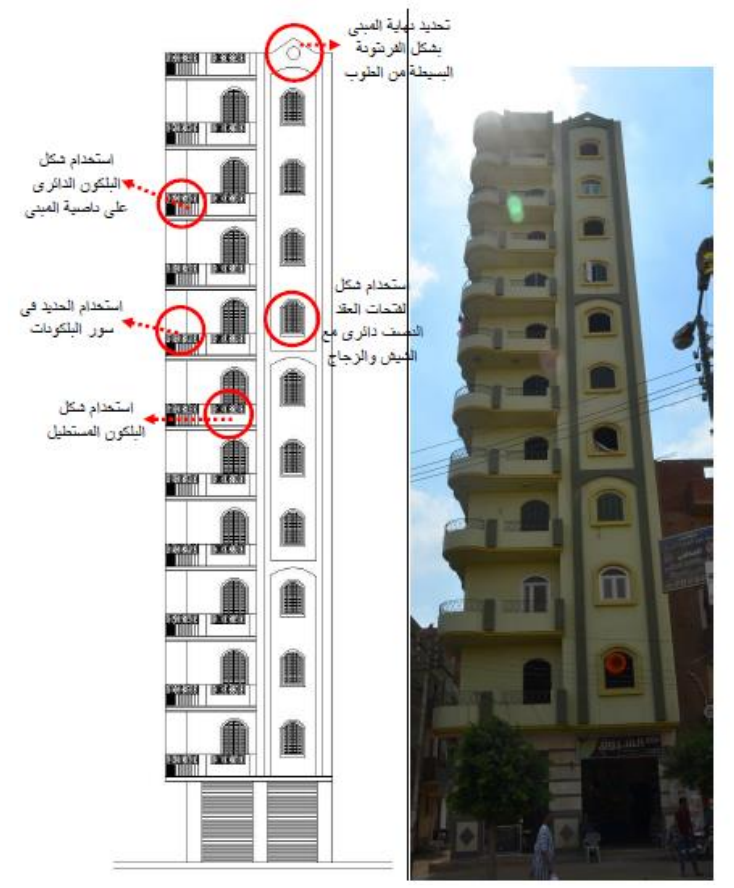

شكل (13) بر سكنى فى شار ع ميت خاقان، شبين

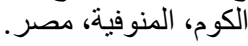
المصدر: الباحث

2) النموذج (2) برج سكنى مكون من 11 طابق تم استخدام النظام الهيكلى فى الانثاء كما هو موضح (بالثن من النشل 14).

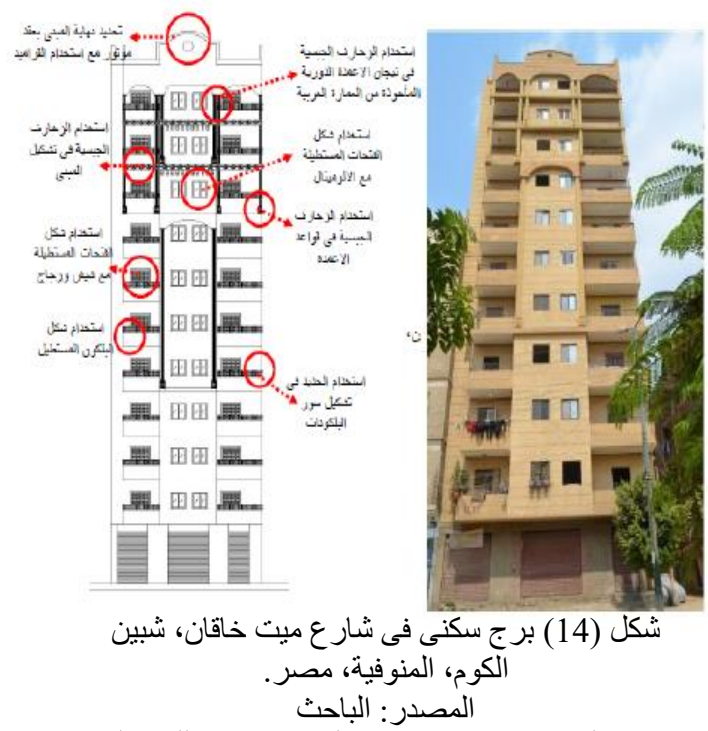

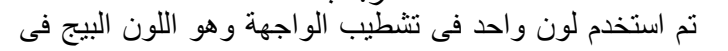
الاظهار وتثطيب الواجهة.

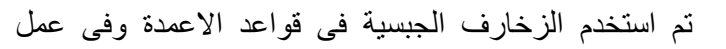

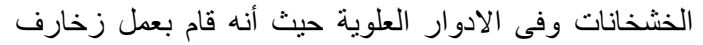

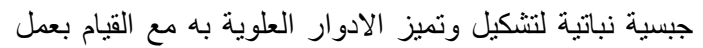
تيجان للاعمدة. • تم استخدام شكل التراس المستطيل. تم استخدام شكل الفتحات المستطيلة حيث تم استخدام الالومنيوم

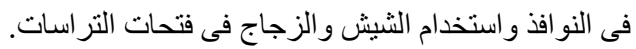

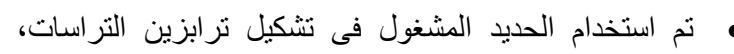
واستخدام الاعمدة الرومانية المكونة من قاعدة العمود وبدن
• تم استخدام شكل الفتحات العقد النصف دائرى فى كافة الفتحات

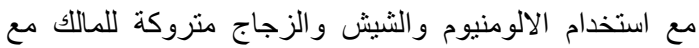

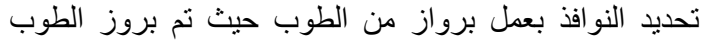
مقدار ربع طوبة وتنطييها بلون مختلف يميز النو افذو وهو اللون يرن

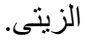
• • تم استخدام الحديد المشغول فى تشكيل تر ابزين التراسات.

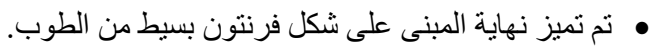

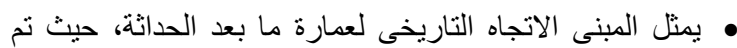

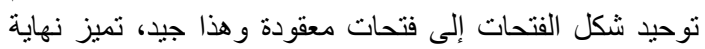

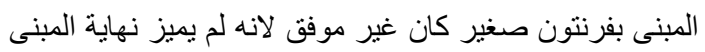

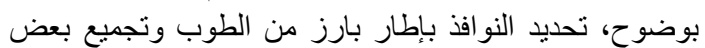

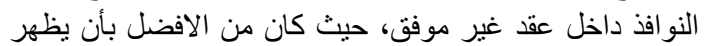
العقد بثكل أوضح ويكون له وظيفة مع الثكل في المبنى.

\begin{tabular}{|c|c|c|c|}
\hline شياخة ميت خاقان & \multicolumn{2}{|c|}{ الموضوع } & a \\
\hline$\% 9$ & من دور إلى دورين & \multirow{3}{*}{ الارنقاعات } & \multirow{3}{*}{1} \\
\hline$\% \leqslant 9$ & من "آدوار إلى هأدوار & & \\
\hline$\%$ \% r & أكثر من 1 أدوار & & \\
\hline$\% 94$ & نظام هيكلى & \multirow{2}{*}{ نظام الاثشاء } & \multirow{2}{*}{ r } \\
\hline$\%$ \& & حوائط حاملة & & \\
\hline$\% \vee 1$ & جيد & \multirow{3}{*}{ حالة المبنى } & \multirow{3}{*}{$r$} \\
\hline$\%$ \% & متوسط & & \\
\hline$\%$. & ردئ & & \\
\hline$\% \wedge \mu$ & تجارى & \multirow{3}{*}{ 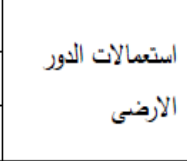 } & \multirow{3}{*}{$\varepsilon$} \\
\hline$\% 1$ & جراج & & \\
\hline$\% 14$ & 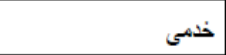 & & \\
\hline$\% \wedge 9$ & سكنى & \multirow{2}{*}{ المتكري الات الدور } & \multirow{2}{*}{ 。 } \\
\hline$\% 11$ & خذمى & & \\
\hline$\%$ \& & يوجد & \multirow{2}{*}{ العناصر الزخرفيه } & \multirow{2}{*}{1} \\
\hline$\% 94$ & ل ايوجد & & \\
\hline$\% 00$ & مستطيل & \multirow{3}{*}{ شكل التزاسات } & \multirow{3}{*}{ v } \\
\hline$\% 1$. & دائرى & & \\
\hline$\% 10$ & |لا يوجد & & \\
\hline$\% \vee \leqslant$ & مستطيلة & \multirow{3}{*}{ شكل النتحات } & \multirow{3}{*}{1} \\
\hline$\% \backslash \leqslant$ & معقودة & & \\
\hline$\%$ ir & متتوعه & & \\
\hline$\%$ \% & الواجهات المشطبة & \multirow{2}{*}{ تشطيات الواجهات } & \multirow{2}{*}{9} \\
\hline$\%$ or & الوجهات الغير مشطبة & & \\
\hline اتجاه عمارة الحداثة & \multicolumn{2}{|r|}{ الاتجاه المعمارى السائد } & 1. \\
\hline$\%$ \% & حيد & \multirow{5}{*}{ العناصر التشكيلية } & \multirow{5}{*}{11} \\
\hline$\%$ \% & برامق & & \\
\hline$\%$. & أعمدة & & \\
\hline$\%$ ir & استخدام عنصرين أو أكثر & & \\
\hline$\%$ \& & ل الا يوجد & & \\
\hline 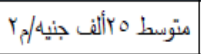 & & متوسط سعر الارض & ir \\
\hline
\end{tabular}

جدول (1) نتائج دراسة منطقة ميت خاقان، شبين الكوم، المصدر : الباحث. 
من الفتحات جيد وهو العقد النصف دائرى فى تشكيل الواجهة،

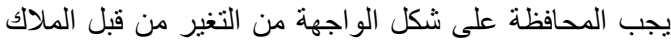

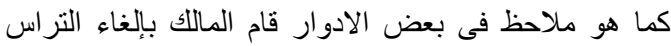

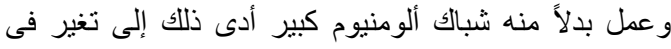

شكل الواجهة و هذا غير مفضل. توني

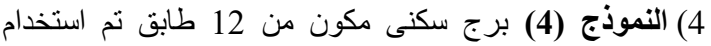

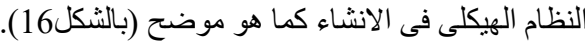

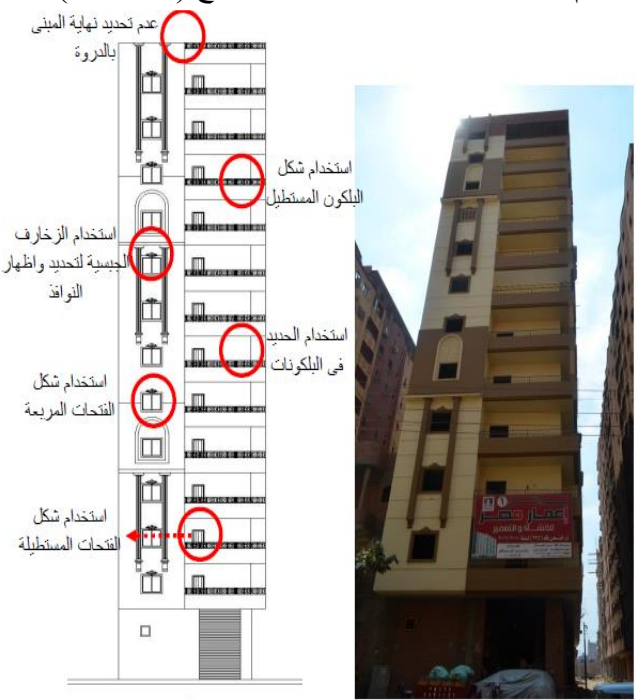

شكل (16) برج سكنى فى شار ع ميت خاقان، شبين

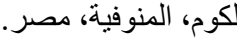
المصدر : الباحث: مثر

• تم استخدام عدة ألوان فى تشطيب الواجهة حيث تم استخدام اللون التئ

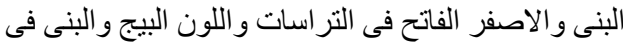
الابر اج وتحديد الفتحات.

• • تم استخدم الزخارف الجبسية لتزين النو افذ وتحديدها. • • • • • م استخدام شكل التر اس المستطيل.

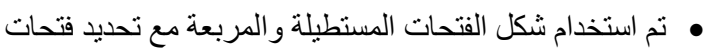
النو افذ بالاعمال الزخرفية.

• م استخدام الحديد المشغول في تشكيل تر ابزين التراسات.

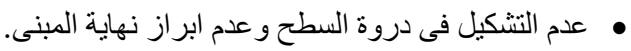

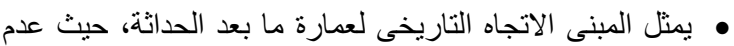

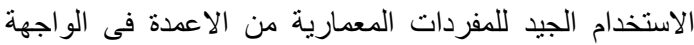

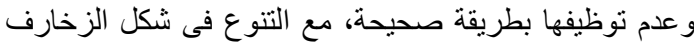

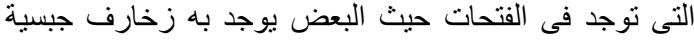
و البعض الاخر زخارف ولكن على شكل عقد حيث توجد الفتحة

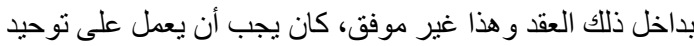

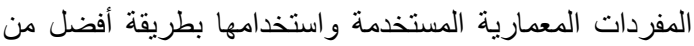

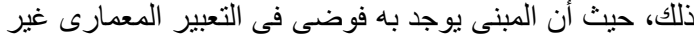

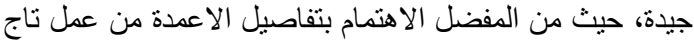

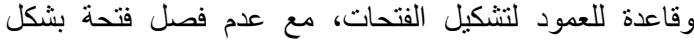

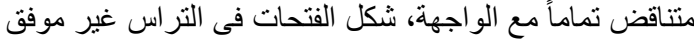

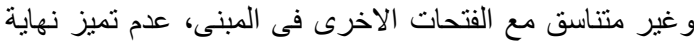

5) النموذج (5) برج سكنى مكون من 11 طابق تم استخدام النظام

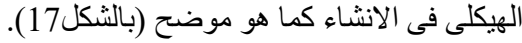

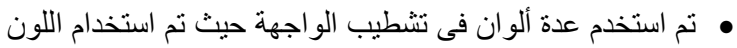

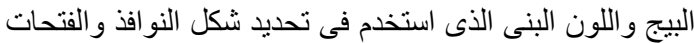
لاظهار ها و فى تحديد البروز لإعطاء مظهر للواجهة.

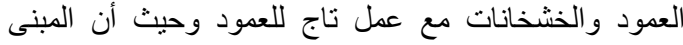

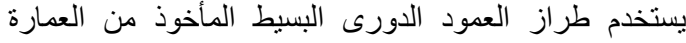

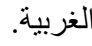

تم تميز نهاية المبنى بعمل دروة من الطوب على شكل عقد موتور مع عمل القراميد المستخدمة فى نهاية المبنى المأخوذة دئة

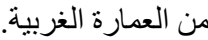

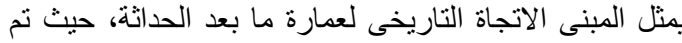

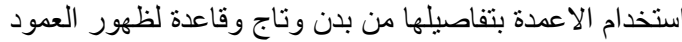

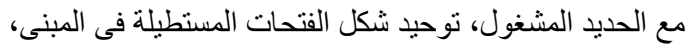

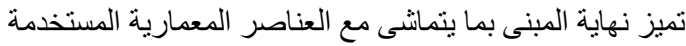

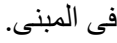
3) النموذج (3) برج سكنى مكون من 13 طابق تم استخدام النظام

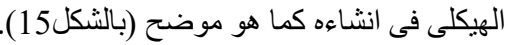

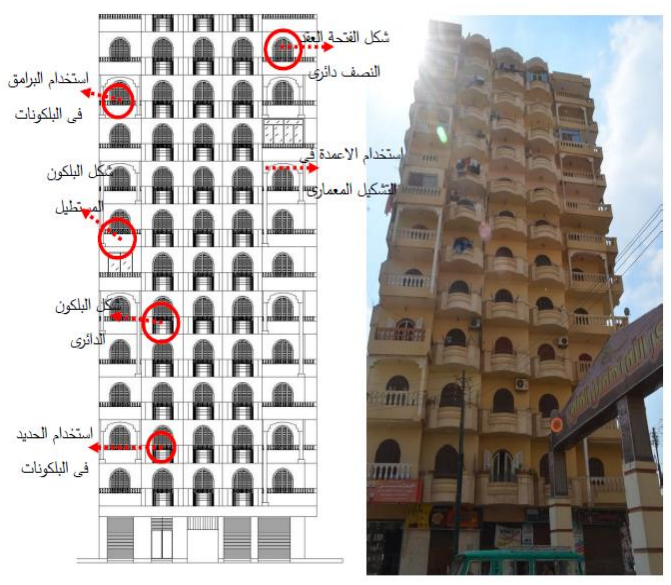

شكل (15) برج سكنى فى شار ع ميت خاقان، شبين

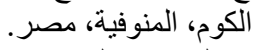

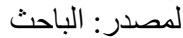

• م استخدم اللون الواحد فى تشطيب الواجهة وهو اللون البيج. • • المبنى لا يوجد به أى زخارف مستخدمة في تشكيل الواجهة.

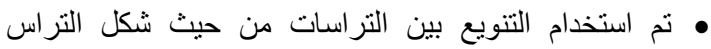

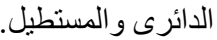

• م استخدام العقد النصف دائرى فى الفتحات، مع استخدام

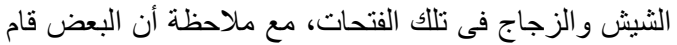

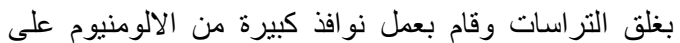

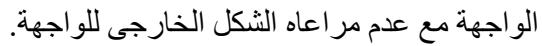

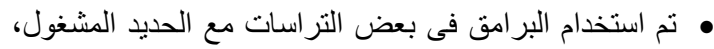

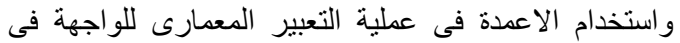

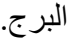

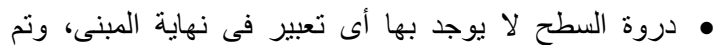
استخدام الحديد و البر امق لترابزين السطح.

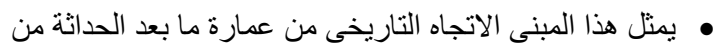

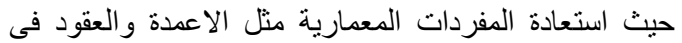

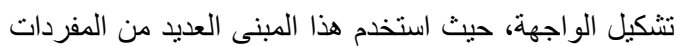

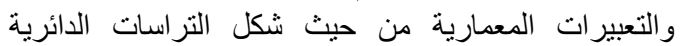

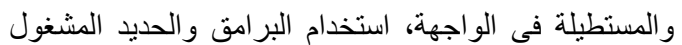
والاعمده فى تزين سور وشكل التراسات، عدم تميز نهاية

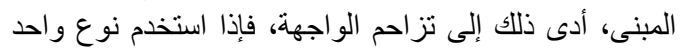

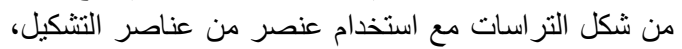

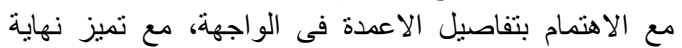

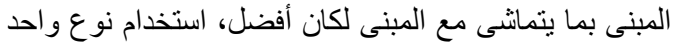


مكسب حيث أنه بريد فى النهاية المكسب، وفى بعض الاحيان

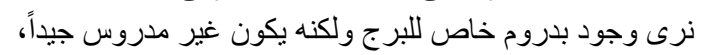

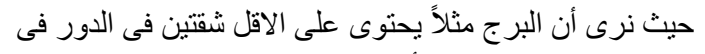

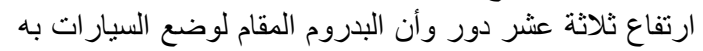

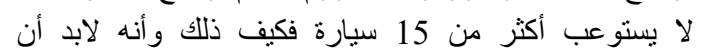

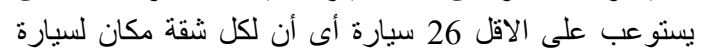

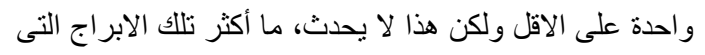

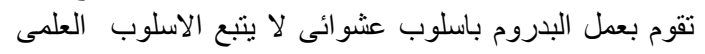

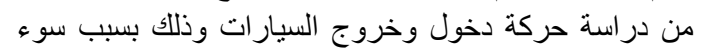

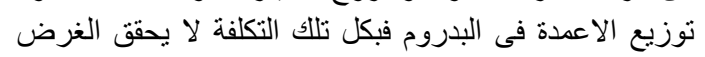

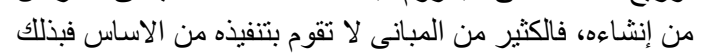

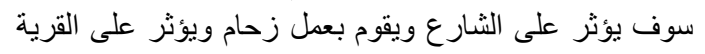

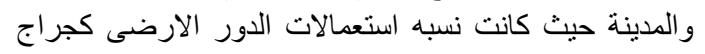

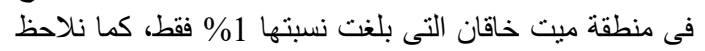
انتشار المحلات التجارية فى استعمالات الدور الارضى لفئ لمنطقة

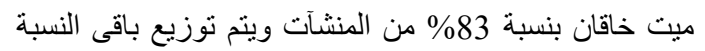

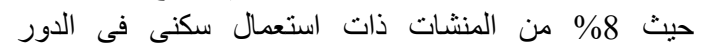

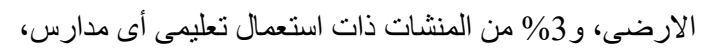

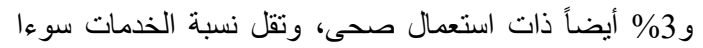

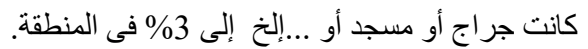

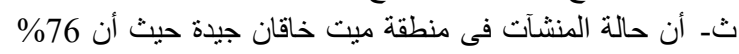

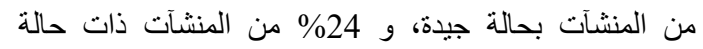
متوسطة.

ج- لا تستخدم العديد من المبانى العناصر الزخرفية فى التشكيل

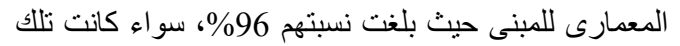

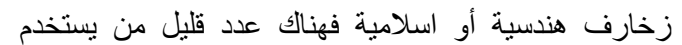

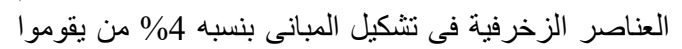

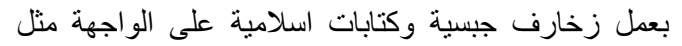

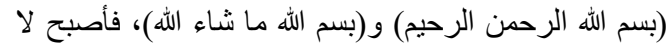

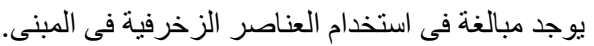

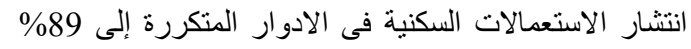

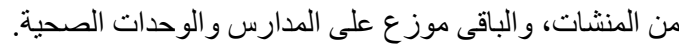

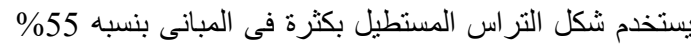

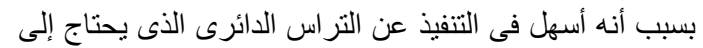

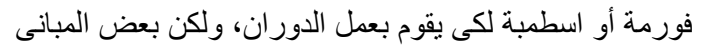

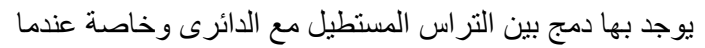

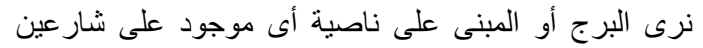
نلاحظ بأن التراس يأخذ دوران عند الناصية والبـ الباقى مستطيل

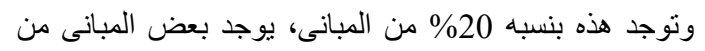

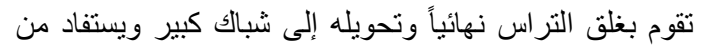

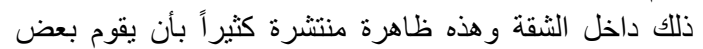

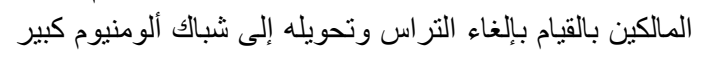

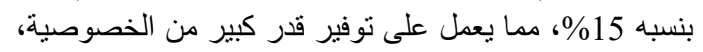
مع تشويه الثكل المعمارى. انتشار شكل الفتحات المستطيلة التى توحى بالبساطة فى التى التعبير

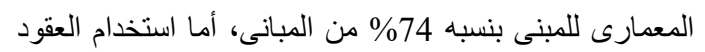

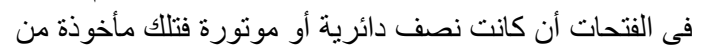
العمارة الغربية والإسلامية التى كانت نستخدم تلك الته العقود

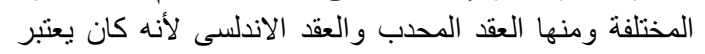

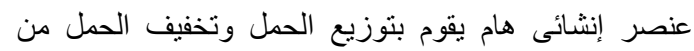

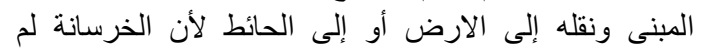

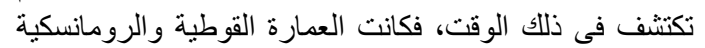

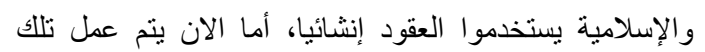

• المبنى لا يوجد به أى زخارف مستخدمة فى تشكيل الواجهة.

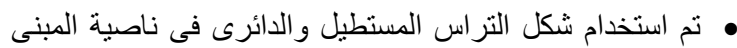
فى عمل تشكيل للو اجهة. • تم استخدام شكل الفتحات العقد النصف دائرى فى الواجهة مع الزع الزعاج استخدام الثيش و الزجاج.

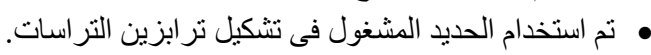

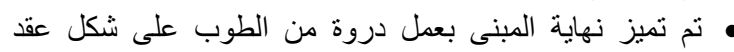

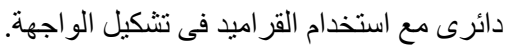

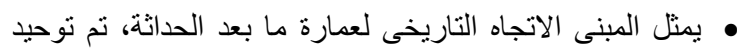
شكل الفتحات بالعقد النصف دائرى فى المبنى، واستخدام القرميد

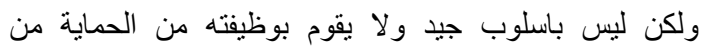

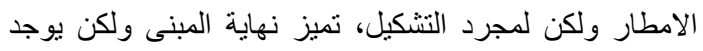

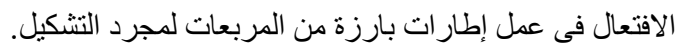

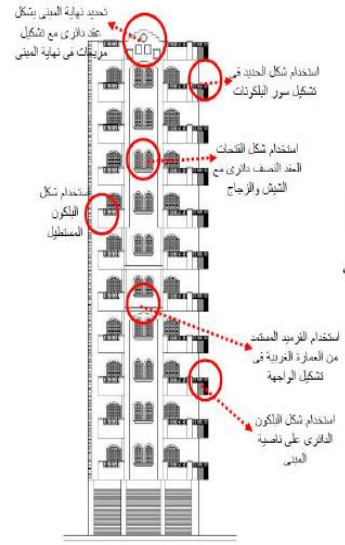

$$
\begin{aligned}
& \text { شكل (17) برج سكنى فى شار ع ميت خاقان، شبين }
\end{aligned}
$$

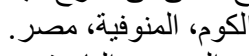

$$
\begin{aligned}
& \text { المصدر : الباحث: المنير }
\end{aligned}
$$

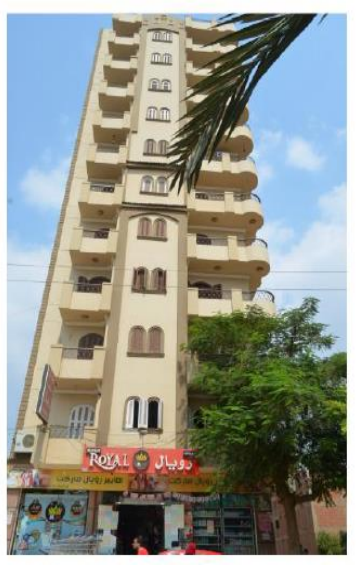

7- نتائج ملامح الطابع المعمارى بمنطقة ميت خاقان

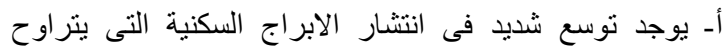

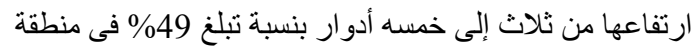

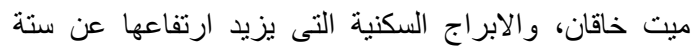

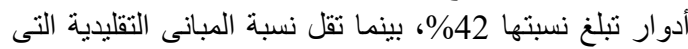

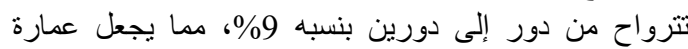

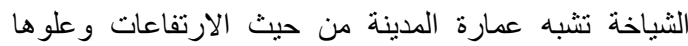

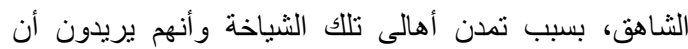

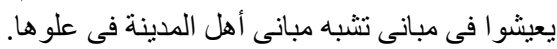

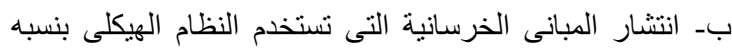

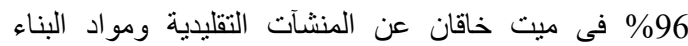

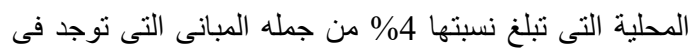

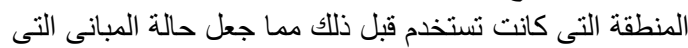
تستخدم الخرسانة أفضل من البيوت التبلت التقليدية.

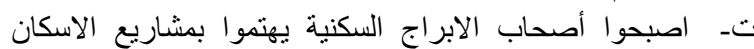

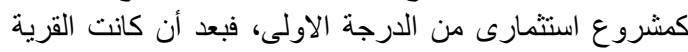

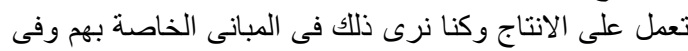

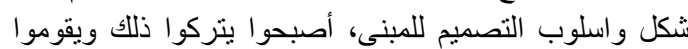

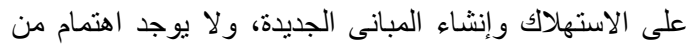

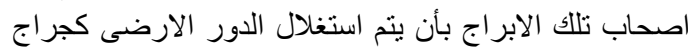

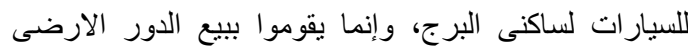

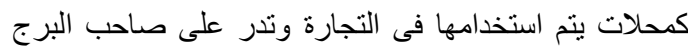
أكبر عائد مادى حيث فى النهاية يريد صاحب التهارة العقار أكبر 
الاتجاه المعمارى السائد فى الثياخة اتجاه عمارة الحداثة، ولكن

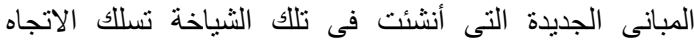

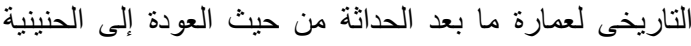

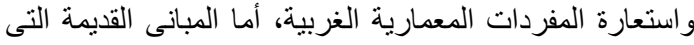

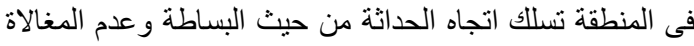

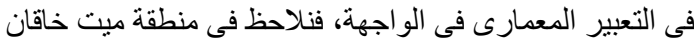

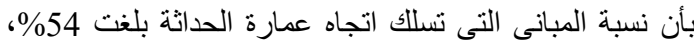
أما المبانى التى تسلك اتجاه عمارة ما بعد الحداثة بلغت 46\%

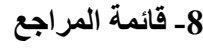

إبر اهيم مصطفى الدميرى، الحفاظ على القيم الجمالية للأحياء

السكنية بمدينة القاهرة، كلية الهندسة، جامعة الفمانة

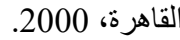

عاصم التركى، أثر التحولات الثقافية المعاصرة على البيئة المبنية دراسة على المناطق الريفية بدلتا مصر.

رسالة ماجستير، كلية الهندسة، جامعة المنوفية،

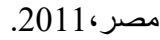

عبد الباقى إبر اهيم، تأصيل القيم الحضارية فى بناء المدينة

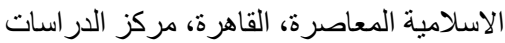

التخطيطية و المعمارية، 1982، ص صداهية 29.

ميرفت عبد العظيم الثافعي ,العمارة ما بعد الحديثة بين النظرية

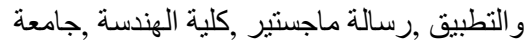

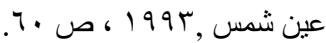

Amiri, N. (2016). Modernism and Postmodernism in Architecture, an Emphasis on the Characteristics, Similarities and Differences, turkish online journal of design, art and communication. TOJDAC, August 2016.

Eco, U, Postscript to the Name of the Rose, in: Jencks. Post-Modernism The New Classicism in Art and Architecture,Academy Edition, London, 1987, P. 18-25

Jencks, Charles, The Language of postModern Architecture, Academy Editions, London, 1984.

Ronald J. Horvath: ADefinition of Colonialism, current anthropology, university of chicago press. vol, 13, No.1. Feb, 1972 ,

pp.
الفتحات فى القيام بعمل تشكيل الواجهات، ويتم استخدام تلكي

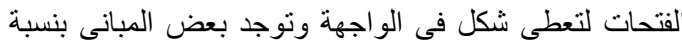
14 \%ن من يقومو ا باستخدام العقود في الفتحات.

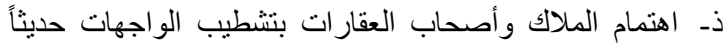

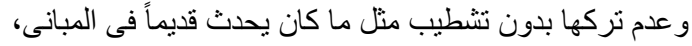

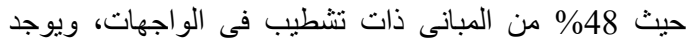

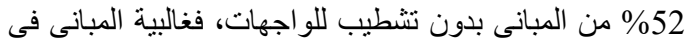

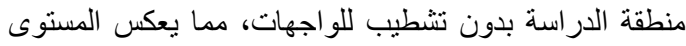

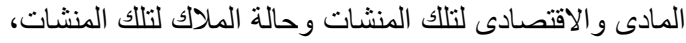

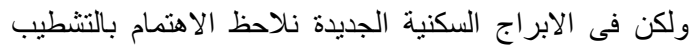

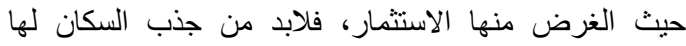

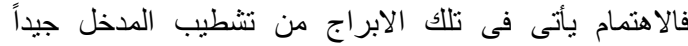
و الواجهة للبرج، فنلاحظ بأن المبانى التى توجد فئ في فئ مدينة شبين

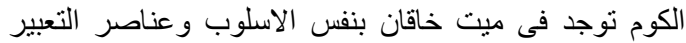

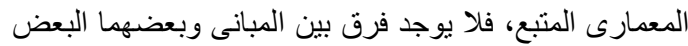

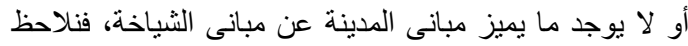

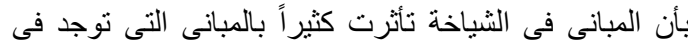

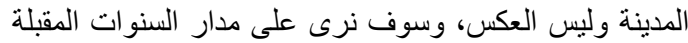

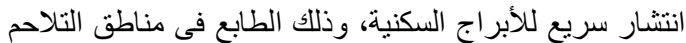

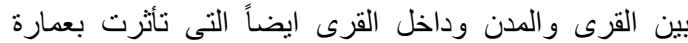

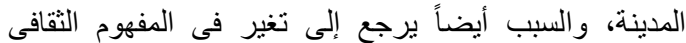
و الاجتماعى لسكان الريف. ر- لا تهنم العديد من المبانى بتحديد وتميز نهاية المبنى بنسبة

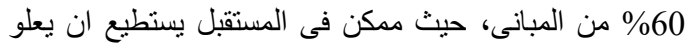

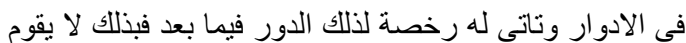

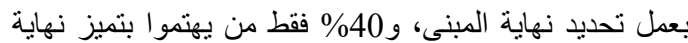

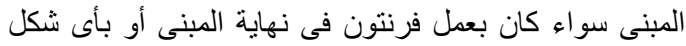
أخر، نلاحظ بعض من الملاك قاموا بتغير تشطيبات الوحدات

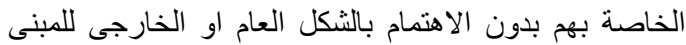

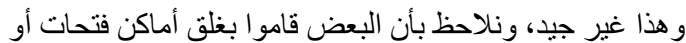
تر اسات وبذللك يشوه من شكل الو اجهة و المبنى.

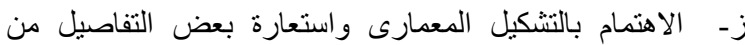

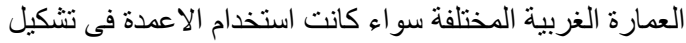

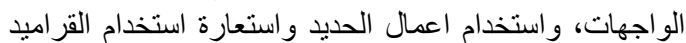

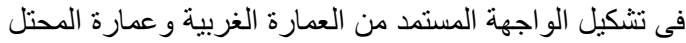

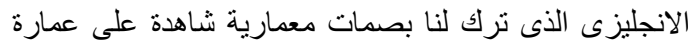

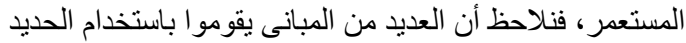

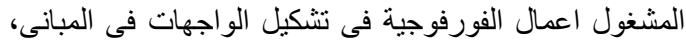

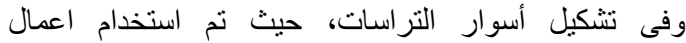
الفورفوجية فى العمارة الغربية وخاصة فى عصر الرئية الروكوكو

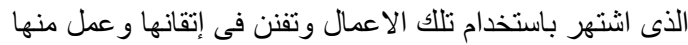

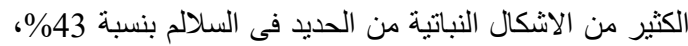

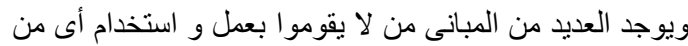

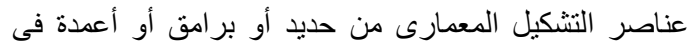

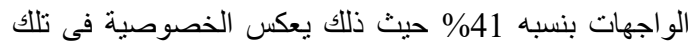

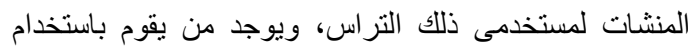

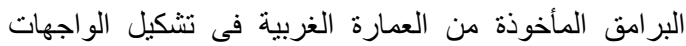

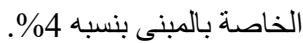

